\title{
MANIFESTACIONES ÉTNICAS Y CÍVICO-TERRITORIALES DE LOS NACIONALISMOS
}

\section{Araceli Serrano Pascual ${ }^{1}$}

Universidad Complutense de Madrid

\section{RESUMEN}

En este artículo se realiza un estudio comparado de las manifestaciones de los discursos nacionalistas en los contextos vasco y catalán. Se ha partido de la existencia de un conjunto de elementos básicos de los que arranca el desarrollo de todo discurso nacionalista (el "código" en términos lingüísticos) que se hace concreto en contextos específicos adoptando formas variables en las que se priorizan elementos diversos («hablas nacionalistas»). Los diferentes discursos oscilan entre dos polos «ideal-típicos» de manifestación del nacionalismo, uno es el polo étnico y otro el cívico-territorial. Las posiciones concretas en el continuum formado por estos dos polos dependen de características como los grupos que constituyen su principal soporte, las tradiciones ideológicas predominantes o el contexto cultural, político y económico en el que se desenvuelven.

\section{INTRODUCCIÓN}

En este artículo se analizan las maneras en que se articulan diferentes elementos y símbolos constitutivos de nacionalidad en forma de discursos nacionalistas. Se parte de la definición de nacionalismo como un discurso que

${ }^{1}$ Este artículo está basado en un capítulo de mi tesis doctoral. Aprovecho este espacio para expresar mi más sincero agradecimiento a Julio Carabaña y a Fernando Conde por su colaboración y contribución a la misma.

\section{Reis}


construye la nación, narrándola, dándola coherencia, continuidad y plausibilidad y, al mismo tiempo, seleccionando los elementos significativos que marcan la diferencia con otros grupos nacionales.

Se desarrolla un análisis basado en la consideración de la existencia de un "código nacionalista» (en términos lingüísticos sería «la lengua») constituido por un conjunto de reglas comunes - teóricas - que vendrían a conformar la nación, toda nación. Son normas que se aspira a cumplir (aunque nunca se consiga). Sería la doctrina nacionalista, o la core-doctrine descrita por Smith (1976) o lo que Cabrera Varela (1992: 14) llama «el núcleo fundacional común del nacionalismo». Éste incluiría, fundamentalmente, rasgos como la coincidencia de unidades culturales y políticas, la existencia de un territorio nacional, la soberanía (o mayor grado de autonomía) de las naciones y el principio de autodeterminación de los pueblos. Por otra parte, encontramos manifestaciones concretas de estas reglas que son más aspiraciones que realidades. Son las "hablas nacionalistas» o narraciones ${ }^{2}$ de la nación, que vienen a ser las diversas realizaciones individuales (o grupales), el uso de esas normas y la combinación particular de elementos, engarzados de forma diferente según el contexto, los grupos sociales, los intereses o la situación económica. No todas las «hablas» tienen un valor equivalente. Están las que podemos llamar «hablas hegemónicas» ${ }^{3}$, que son aquellas que cuentan con más poder (económico, político o cultural) para imponer su propia versión como «evidencia social» (PérezAgote, 1986). En este sentido, destacan las articulaciones de los discursos hechas por los partidos políticos (especialmente de aquellos que están al frente del gobierno en un contexto concreto - a nivel nacional o subnacional-), el control de los medios de comunicación, así como la historia de los nacionalismos y de las tradiciones ideológicas predominantes. Por otra parte, encontramos las "hablas especificas» de diversos grupos sociales. Todas estas «hablas» coexisten en un contexto determinado e implican interpretaciones específicas del código general.

En este texto se analizan los casos vasco y catalán, considerando las diversas manifestaciones y las articulaciones discursivas presentes en ambos.

La delimitación que hacemos de los discursos nacionalistas se basa en la propuesta de Smith $(1986,1991)$. Este autor parte de la existencia de dos tipos básicos de nacionalismo, uno de carácter étnico y otro que denomina cívicoterritorial. El tipo cívico está caracterizado por una concepción predominantemente espacial o territorial de la nación, en la que destaca una orientación

2 En términos de Bhabha (1992).

3 Se adopta el concepto «hegemónico» en el sentido gramsciano, contemplando la "hegemonía» como un proceso por el que determinados grupos sociales, en un contexto determinado, ejercen un control (moral, intelectual) sobre otros grupos. Este control no es el resultado de una imposición ideológica directa, sino que implica un proceso por el que dichos grupos articulan principios que integran elementos que se hallan en las cosmovisiones, prioridades e intereses de los demás grupos sociales. Hay que recordar que, en la obra de Gramsci, la conquista de la hegemonía precede a la conquista del poder (Texier, 1975: 40). 
hacia propósitos e intereses comunes y un fuerte sentido de comunidad política y legal. Se pone especial énfasis en la igualdad política, en la cultura e ideología cívica común, así como en la participación y la educación civil. Por otra parte, señala este autor (Smith, 1991: 12-13), la concepción étnica de la nación se caracteriza por hacer hincapié en la "comunidad de nacimiento" y de cultura nativa. Se encuentra relacionada con una idea de nación como «superfamilia ficticia», centrada principalmente en el mito de «descendencia común». El lugar de la ley en el primer modelo es ocupado por la cultura vernacular, normalmente lenguas y costumbres, al tiempo que se crea una conciencia de mitos, historia y tradiciones lingüísticas de la comunidad. Así, como tipos ideales, se puede apelar a la nación en términos de "comunidad de convivencia» (en un territorio con unas características), o de "comunidad de nacimiento» en el seno de una superfamilia ficticia.

Entre estos dos modelos «ideal-típicos» oscilan las diferentes "hablas» que anteriormente se han señalado. Se asume la presencia simultánea de rasgos de ambos en cualquiera de los discursos nacionalistas. La diferente ponderación de elementos de uno u otro tipo depende de las características socioeconómicas, así como de los atributos estructurales de los grupos que los formulan. Se postula que las condiciones que favorecen la aproximación a uno u otro de los tipos ideales mencionados tienen que ver con la posición de los sujetos en contextos de mayor o menor estabilidad, así como en la concreta distribución de los recursos económicos, políticos y culturales. A su vez, hay que considerar que estas "hablas» diversas no se encuentran aisladas, sino que se desarrollan en un mismo contexto, en procesos de interacción y competencia, estableciendo entre sí conexiones estratégicas.

\section{METODOLOGÍA Y FUENTES}

En tanto en cuanto el objetivo que nos proponemos es el del análisis de la producción diferencial de discursos ideológicos nacionalistas (que atañe, por lo tanto, a un tipo de realidad simbólica), la técnica de análisis que resulta más apropiada es aquella mediante la cual se "producen» discursos que, posteriormente, pueden ser analizados. Ya se ha señalado que uno de los presupuestos de los que parte este análisis es que dichos discursos no son fijos, sino que dichas elaboraciones verbales se construyen intersubjetivamente en un proceso de interacción y producción de sentido, en el que se calculan, modulan e incluso transforman los elementos componentes del mismo. La técnica de producción de información que se aproxima, en mayor medida, a esta situación de producción de discursos en interacción, que nos permite investigar el contenido, la naturaleza y la significación de los símbolos que operan, vendrá a ser el grupo de discusión. Con él se puede analizar el objeto que nos interesa -en este caso el nacionalismo- a través de la experiencia que de él poseen un cierto número de individuos que al interactuar combinan y homogeneizan «opi- 
niones, imágenes y representaciones personales en discursos más o menos tópicos que tienden a representar a los grupos sociales que los enuncian» (Alonso, 1995: 227).

Hemos contado para el presente estudio con doce grupos de discusión para el caso vasco y con nueve para el contexto catalán ${ }^{4}$. La composición de los mismos y sus características figuran en el anexo metodológico. El trabajo de campo se llevó a cabo en el final de 1986 y en 1987. Ello quiere decir que la realidad social a la que se refiere este texto es la de aquel entonces. Es un espacio temporal privilegiado para analizar ambos contextos, ya que son precisamente estas fechas cuando se puede considerar se consolida el proceso de institucionalización del nacionalismo y la participación simultánea en la gobernabilidad de España. Muchos han sido los cambios operados en los diferentes discursos nacionalistas desde entonces hasta nuestros días, así como en la práctica política cotidiana en ambos espacios: hiperfragmentación del voto en el País Vasco, pactos tripartitos en el gobierno vasco, pacto de Ajuria Enea, activación de «la calle» por parte del nacionalismo vasco radical, progresivo protagonismo de los grupos pacifistas, contestación abierta al nacionalismo, participación en la gobernabilidad de España de los partidos nacionalistas, intentos de modificación de la Ley de Normalización Lingüística en Cataluña, y un largo etcétera de acontecimientos que ponen de relieve la gran cantidad de circunstancias cambiantes que han caracterizado los últimos años de las manifestaciones de los nacionalismos contemporáneos. Frente al gran volumen de reflexión teórica y ensayística que se ha desarrollado en el análisis de estos recientes fenómenos, la investigación empírica sobre los mismos es, sin embargo, bastante limitada 5 .

\section{«HABLAS HEGEMÓNICAS» SOBRE LA NACIÓN EN PAÍS VASCO Y CATALUÑA EN LA SEGUNDA MITAD DE LOS AÑOS OCHENTA}

A partir del análisis del material producido por los grupos de discusión se han desvelado dos discursos «hegemónicos» que ilustran dos formas de concebir la nación y, por lo tanto, de organizar las percepciones, los sentimientos y la identidad. A modo de resumen inicial, señalamos los principales rasgos de estos discursos que caracterizan nuestros contextos de análisis.

En el caso vasco se ha localizado un nacionalismo de tipo, básicamente, étnico, con especial hincapié en los ancestros, la historia y la proyección de

${ }^{4}$ Estos grupos de discusión son un valioso material que nos ha ofrecido el equipo de la empresa de investigación Comunicación, Imagen y Opinión Pública (CIMOP), a través de la generosa mediación de Fernando Conde. Las investigaciones fueron encargadas por el CIS con el objetivo de conocer la situación sociopolítica de ambos contextos.

5 Al lector interesado en análisis empíricos actualizados sobre estos contextos remitimos a los textos de Ayerbe et al. (1996), Estradé (1989), García Ferrando et al. (1994), Gurrutxaga (1990), Llera Ramo (1992), López-Aranguren (1995), Mata (1993), Keating (1996), etc. 
pasado, la cultura común y la solidaridad intracomunitaria, con importantes concepciones dualistas de la sociedad y unanimistas del nosotros ( $\sin$ fracturas $)^{6}$. La comunidad se presenta fundamentalmente como un tipo de "comunidad de historia» con escasa proyección de futuro. Destaca la precariedad de la dimensión "civil» de este tipo de nacionalismo, marcado también por la no participación en la aceptación de la norma básica (la Constitución), que constituye uno de los puntos de partida fundamentales del desarrollo de una concepción de la nación de tipo cívico. En el momento en el que fue realizado el trabajo de campo, se puede decir que el País Vasco se encontraba en proceso de transición (dolorosa, traumática) hacia un nacionalismo de tipo cívico-territorial, acompañado de un reconocimiento y aceptación de las diferencias internas y la emergencia de las concepciones individualistas ${ }^{7}$. Se produce así una ruptura de la concepción dualista de la sociedad (en términos de nosotros/ellos). En este nuevo panorama coinciden, en un momento concreto, un rápido proceso de diferenciación social, la hiperpolitización de la vida en el País Vasco, la conciencia de las dificultades del proceso de normalización lingüística y la división de la familia nacionalista, dando como resultado un resquebrajamiento de la "comunalidad mítica vasca», que va siendo sustituida por una concepción disgregada e inserta en el juego político de partidos y electoralista en el sentido moderno (estas características y procesos se irán explicitando en los siguientes apartados).

El nacionalismo catalán, por otra parte, adopta características de un tipo de «autonomismo de enfrentamiento» en un proceso de competencia por recursos y poder del Estado. El discurso nacionalista predominante en Cataluña puede ser considerado como un prototipo del sistema autonómico español, con el ejercicio de un tipo de política coyuntural y estratégica, de presión sobre el Estado en la búsqueda de obtención de recursos, poder y competencias (sirviendo al mismo tiempo como discurso legitimador y exculpatorio) ${ }^{8}$. Al mismo tiempo, se entrevé la progresiva conciencia de la falta de dinamismo y estancamiento de esta estrategia. Aparece un tipo de concepción positiva de la competencia política, así como la asunción de la individualidad y el personalismo (frente a la importancia de la concepción comunitaria en el caso vasco) y de las diferencias en el seno de la propia comunidad, que son susceptibles de ser integradas bajo el paraguas de un proyecto común de bienestar económico y mejo-

${ }^{6}$ Esta concepción unanimista del «nosotros» que ha caracterizado buena parte de los procesos identitarios en el País Vasco comienza a resquebrajarse precisamente en estas fechas, emergiendo, desde entonces, nuevas formas fragmentadas de manifestación de la identidad nacional y del nacionalismo, hasta desembocar en un contexto marcado no ya sólo por la diferenciación interna sino, frecuentemente, por el enfrentamiento.

Gurrutxaga y Unceta (1995) señalan también la transición del discurso nacionalista en el País Vasco, que comienza a producirse a partir de la «entronización de la democracia» y que supone un cuestionamiento de la «doctrina central» nacionalista vasca.

8 Esta estrategia ha venido multiplicando su operatividad desde el momento en que la opción nacionalista en el gobierno se convierte en pieza clave en la gobernabilidad del Estado español. 
ra social. La comunidad aparece fundamentalmente en términos de "comunidad de destino" y de proyecto. Se aproxima básicamente al tipo de nacionalismo que Smith ha denominado cívico-territorial, centrándose en el territorio, la economía común, las leyes, el sistema educativo y, sobre todo, la "comunidad de lengua" como elemento inclusivo de identificación que implica posibilidades de adopción.

En cualquier caso, cada manifestación particular del nacionalismo se realiza mediante un tipo de selección de una serie de elementos, características, sucesos y prácticas que hacen referencia tanto a aspectos culturales, como sociodemográficos, históricos, económicos y políticos inyectados de una buena dosis de ambigüedad que garantiza la posibilidad de interpretaciones y atribuciones de significados diferentes según el contexto en el que se desenvuelvan.

En nuestro caso, somos conscientes de que en este estudio no se recoge toda la gama de características, símbolos, mitos, actividades, estrategias y actitudes que componen la globalidad de los discursos sobre la nación en uno y otro caso. Se hace referencia, única y exclusivamente, a aquellos aspectos que se muestran en el material empírico con el que contamos para realizar este análisis.

El análisis de los discursos obtenidos se ha segmentado en tres grandes apartados; a saber, la descripción de lo principales elementos priorizados en el discurso, el tratamiento de la identidad y la alteridad y, por último, la dimensión más estrictamente política.

\section{Elementos diferenciales priorizados}

Los rasgos tomados en cuenta en la elaboración de los discursos serán aquellos que resultan significativos para la población y que son pragmática y simbólicamente rentables. Es decir, se entresacan elementos que pueden ser eficazmente utilizados en procesos de competencia con otros grupos y que se creen útiles para marcar la diferencia con los que no pertenecen a dicho grupo, para delimitar la frontera con «el Otro». Se tratará de dar un cierto carácter coherente a la articulación de estos elementos evitando las contradicciones y engarzándolos en una estructura lineal, en una especie de trama narrativa que dé continuidad al proceso de construcción de identidades.

En el País Vasco encontramos un predominio de referencias a aspectos genealógicos conectados, en mayor medida, con la simbología de la familia, la comunidad de nacimiento, en un sentido de nación como descendencia común y comunidad de historia. Los términos que predominan están relacionados con el parentesco («hermanos», «familia», "tronco común»), no sólo en la especificación de lo que es lo vasco, sino incluso en la propia retórica relacionada con los partidos políticos, al referirse continuamente unos a otros en términos familiares o generacionales («expulsión de la familia nacionalista», etc.). 
Se localiza frecuentemente una orientación hacia el pasado, la historia, la recuperación de derechos perdidos (con un especial hincapié en el concepto de pérdida más que en el de proyecto de futuro). En este proceso de reelaboración de la historia cobran especial importancia los elementos que contribuyen a poner de relieve la intemporalidad (mitos fundadores, origen común, etc.) del grupo nacional. Se reconstruye una historia en la que el carácter defensivo adquiere una relevancia especial, haciendo hincapié en la persecución secular de lo vasco como argumento que da continuidad y coherencia a la reconstrucción del pasado y que, a su vez, contribuye a dar sentido a su presente. La reconstrucción de la historia se elabora a partir de la incorporación de un nuevo «mito fundacional»: el franquismo (coincidiendo con el análisis de Pérez-Agote, 1987), el cual consigue proveer de un "mito de renacimiento" a la comunidad vasca. Con la memoria del franquismo, se asiste a un proceso de unificación de lo vasco frente a la dictadura y a lo que significó la opresión de su distintividad y de las señas de su identidad.

Las fechas de realización del trabajo de campo constituyeron un momento de grave crisis económica y de fuerte desintegración social en el seno de la sociedad vasca. En este contexto, la sensación de fatalismo respecto al futuro reforzaba la tendencia evidenciada hacia la nostalgia del pasado. Se percibe una falta de planificación y una carencia de un proyecto de futuro que conlleva posiciones y actuaciones que se van negociando sobre la marcha de los acontecimientos. Esta falta de posicionamiento y horizonte desemboca en una sensación de precariedad, una "falta de ilusión» y, en consecuencia, una búsqueda de coordenadas de orientación en el pasado. A estas posiciones se añade la consideración de un cierto proceso de desplazamiento del resto del mundo, de los centros de poder y toma de decisiones.

Emergen, continuamente, señales y marcas diferenciadoras, símbolos de identidad y pertenencia que marcan la especificidad y la identificación con la comunidad nacional. Destaca la apelación a la ikurriña, al euskera, al himno y la ertzaintza. En definitiva, aquello que contribuye a poner de manifiesto la diferencia, la especificidad, se constituye en símbolo de pertenencia. Estos símbolos permiten al individuo experimentar la frontera de lo nacional. Cara a su operatividad como aglutinadores sociales, dichos símbolos de pertenencia son dotados de legitimidad histórica, oscureciendo el reconocimiento del cambio y haciendo así convincente la apariencia de continuidad.

Otra característica autoatribuida como prototípica y conformadora del «carácter nacional» que aflora continuamente en el discurso es el comunitarismo vasco. El mito del igualitarismo y del comunitarismo (obviando las estructuras de diferenciación internas) ha constituido frecuentemente un poderoso aspecto simbólico de activación de la solidaridad intragrupal. Se encuentra, también, una sobrevaloración del «sentimentalismo» por encima del «racionalismo» que redunda en una percepción de su sociedad caracterizada por un tipo de solidaridad mecánica (en términos durkheimianos) basada fundamentalmente en comportamientos afectivos más que racionales. 
Se observa, asimismo, la valoración positiva del pasado rural. Es el grupo de los campesinos, caseros y pastores, aquel en el que descansan los atributos conferidos al "vasco auténtico», del carácter peculiar idealizado, antes de producirse el proceso de "contaminación» (industrialización).

Otro elemento fundamental en la articulación de este tipo de discurso es la lengua. Ésta ha sido frecuentemente contemplada como la característica esencial de la nación misma y la fuente fundamental de identidad colectiva. Destaca la importancia de este elemento tanto a nivel simbólico (atributo de diferencialidad más fácilmente objetivizable) como a nivel instrumental (recurso de comunicación, de inserción y de promoción social). La lengua se presenta como el principal medio diferenciador de lo vasco ensalzando su originalidad y exclusividad. El euskera viene a ser un elemento que condensa en sí mismo parte importante de la represión sufrida durante el franquismo. Su antigüedad es mantenida como estandarte de diferenciación y justificación de la igualdadinmutabilidad de un pueblo. La lengua se constituye, así, en el principal medio de conquistar el estatus nacional, convirtiéndose paralelamente en una vía de consecución de estatus social. No obstante, cabe destacar la mayor importancia del aspecto simbólico que de su valor instrumental. A pesar de esto, en las fechas en que fue realizado el trabajo de campo se estaba produciendo una transformación de esta concepción eminentemente simbólica en otra de carácter más pragmático. La lengua se muestra como un elemento altamente rentable en el nivel político y cultural, así como un recurso valioso en la competencia por puestos de trabajo. A pesar de todo esto, el euskera, tanto por el estado de recesión en que se ha encontrado como por la dificultad de su aprendizaje, es vivido desde una posición traumática. Esta circunstancia es usada por los diferentes discursos y versiones como una especie de arma arrojadiza contra el grupo contrario, utilizando la dificultad del proceso de normalización lingüística para desprestigiar y culpabilizar al «otro». Dicha dificultad en el proceso de euskaldunización hace que, en el mismo caso de los nacionalistas, la ligazón entre nacionalismo y euskera sea evitada (eludiendo, así, en función de las circunstancias uno de los elementos más efusivamente defendidos por la mayor parte de los teóricos nacionalistas).

Por otra parte, en Cataluña encontramos un mayor predominio de metáforas y símbolos relacionados con el territorio, ligados en mayor medida a un proyecto común y a un sentido de comunidad político-legal. La nación se constituye en lugar de convivencia, de coparticipación en experiencias comunes. Aparecen referencias metafóricas a Cataluña como casa, como lugar-territorio de vivencia colectiva (con las consiguientes connotaciones de «la casa» como lugar-habitáculo común, en la cual se comparte un techo protector conjunto). Se observa una fuerte orientación hacia el futuro - comunidad de destino- (aunque más se habla de tendencias que de metas, de proyectos más que de objetivos claros). El medio fundamental para la consecución de sus aspiraciones vendrá dado por la constante demanda al Estado y al Gobierno central (demandar más como estrategia de posicionamiento). Destaca un 
ambiente general de optimismo, reforzado por su posición privilegiada económicamente en el seno del Estado español. El proyecto nacional se presenta como algo a construir y desarrollar por todos los que viven y trabajan en Cataluña. No obstante, se muestra la necesidad y efectividad del aprendizaje de «ser catalán» (a través del conocimiento de su historia, costumbres y, especialmente, su lengua).

A diferencia del caso vasco, el nacionalismo catalán presenta una dimensión histórica y de clase más concreta. En relación con el carácter diferencial del catalán, encontramos que el prototipo que opera no será el «intangible pueblo catalán» (como sí aparecía en el caso vasco), sino el "burgués catalán, comerciante, hacendado e industrioso". Aparecen, repetidamente, referencias a su herencia fenicia, atribuyéndose la descendencia de este pueblo eminentemente comerciante.

Otro de los rasgos que aparecen es el pragmatismo, en sus múltiples versiones ${ }^{9}$, así como la valoración del pactismo, de la competencia, de la racionalidad, de la cooperación por consenso (cooperar conjuntamente por acuerdo de todos, para el beneficio de todos) y de la negociación. También se encuentran repetidas referencias a su adaptabilidad y maleabilidad, siempre en actitud de «avanzar posiciones» en lo que constituirían sus objetivos como pueblo.

Los elementos simbólicos que frecuentemente emergen en el discurso como conformadores de identidad y marcas de diferencia son la senyera, la Generalitat, la lengua, los acontecimientos, festividades y personajes históricos con mayor carga simbolizante, himnos y consignas de carácter político, así como una cierta conciencia de haber constituido la progresía cultural y política en el seno del Estado español.

Es la lengua el principal rasgo sintetizador de la diferencia catalana y simbolizador de su especificidad. Con ella se establece un tipo de relación muy diferente a lo que vimos en el País Vasco. En Cataluña se prima la diferencia del catalán, mientras en el País Vasco se enfatiza más su exclusividad, su originalidad («hecho diferencial» frente a «hecho único»). Frente a la posición recesiva y defensiva que vimos en el caso del euskera, el catalán se ha convertido en lengua hegemónica en todo el espacio de comunicación social, constituyendo, además, un medio fundamental de integración social y laboral. Este hecho, junto a la mayor facilidad de su aprendizaje, ha potenciado su asentamiento y un ágil proceso de normalización lingüística. El tema lingüístico no se muestra como un tema problemático cara a la política institucional. Se acepta la situación de bilingüismo como consecuencia de la relación no defensiva sino hegemónica con la lengua catalana, si bien sí se experimentan conflictos por el lenguaje a nivel cotidiano ${ }^{10}$. La lengua es vivida como bandera política (pero no

9 Destaca la importancia asignada en la cultura catalana a la noción de seny, relacionada con un espíritu práctico, de "pies en la tierra», que recompensa el cálculo y el compromiso.

${ }_{10}$ Conflictos que tenderán a incrementarse en los años noventa a partir de las propuestas de modificación de la Ley de normalización lingüística. 
como un «arma arrojadiza», como veíamos en el caso vasco) y la política de normalización lingüística constituye una de las principales vías de legitimidad política y de rentabilidad institucional.

En términos generales, se ha observado cómo en el caso vasco, centrado básicamente en la reconstrucción de su pasado y en sus características "étnicas», así como en su mitología y simbología tradicional, encontramos un realce fundamental del aspecto defensivo de la identificación (defensa contra agresiones, contra pérdidas), potenciado por el contexto de crisis económica y por la falta de perspectivas de futuro. En el caso catalán, su mayor hincapié en la lengua como aspecto diferenciador y afirmativo de pertenencia, junto con unas formas de identificación no específicamente ligadas a manifestaciones culturales tradicionales, hace que nos encontremos con un tipo de discurso nacionalista marcado por su carácter asertivo.

\section{Alteridad, identidad y conflicto}

El nacionalismo vendrá a funcionar conectando simultáneamente dos polos de un mismo eje, ofreciendo, al mismo tiempo, pertenencia e identidad con una comunidad cultural específica, así como con una determinada unidad política $^{11}$, posibilitando que determinada agrupación sociopolítica - la nación- se convierta en un tipo de comunidad para los individuos que la conforman. Esta identidad comunitaria nacional viene a construirse a través del lugar que «el Otro» ocupa, ya que dicha comunidad implica simultáneamente similaridad (con el grupo) y diferencia (con el otro). Dicha diferencia puede manifestarse de forma conflictiva o bien complementaria, encontrando la posibilidad del desarrollo de identidades excluyentes, pero también identidades superpuestas y múltiples, en un marco en el que dichas identidades adquieren un carácter dinámico. Así pues, es posible establecer una tipología que oscile entre dos extremos: uno en que se afirme una de las identidades frente a otra, y otro en que se posibilita la convivencia de diferentes identidades sin exclusión, propiciando identidades duales o múltiples. Encontramos tipos de identificación con diferentes esferas que implican grados diversos de compromiso, en función del contexto y de las situaciones sociales concretas. La emergencia de identidades múltiples es, en mayor medida, posible cuando no hay crisis, sensación de hostigamiento, peligro o problematización de alguna de ellas.

Sin embargo, en el primero de los casos que estamos analizando, esto es, el País Vasco, encontramos una situación en la que predomina una importante conciencia de crisis de identidad que lleva a aferrarse fuertemente a las propias señas identitarias, dificultando la emergencia de posiciones duales. Aparecen

${ }_{11}$ En terminología de Gellner (1987), se tratará de hacer de la política y la cultura elementos congruentes. 
continuas referencias a «lo que somos los vascos» o "no somos los vascos», eligiendo fundamentalmente los rasgos de identificación en función de su poder discriminante. Las principales referencias explícitas al establecimiento de criterios de pertenencia tienen relación con la voluntad de integrarse en el pueblo vasco, adoptar sus costumbres, incrementar el conocimiento de su cultura y lengua y, en última instancia, luchar por él, es decir, "ser nacionalista». Así, la principal marca de distintividad se relaciona con la identificación entre Euskadi y nacionalismo, de forma que el nacionalismo activo es percibido como criterio de adscripción a la comunidad. De esta manera, el primer rasgo de identificación que marca la segmentación más importante es la división «nacionalista/no nacionalista». Se adquiere, por lo tanto, la posibilidad de integración a la sociedad vasca a través de la participación en la ideología y actividad nacionalista. Esta dimensión es percibida en términos de oposición, considerándose que aquel que no es nacionalista es antinacionalista y, en consecuencia, antivasco. Predomina una definición de «los otros» no por afirmación, sino por negación (los «no vascos», «los de fuera»), que implica una adscripción y definición de lo ajeno en función de lo que no es como lo propio, lo que queda fuera de lo propio.

En los términos de la construcción discursiva de la identidad nacional encontramos que la nación es pretendidamente puesta por encima de las diferencias internas, clases, adscripciones ideológicas o cualquier otro tipo de segmentación social. Este discurso de la unidad interna, del unanimismo, se percibe como hegemónico y vencedor; ante él se atisban escasas posibilidades de articular otro discurso coherente, que pueda presentarse como alternativa aglutinadora.

En el momento de realización del trabajo de campo, el País Vasco se encontraba en un importante momento de descentramiento y desestructuración del campo del «nosotros» (ligado a la crisis del nacionalismo - escisión del PNV en 1986 - y a la crisis económica, fundamentalmente $)^{12}$. Los otros se ajustaban, hasta un período reciente, al ámbito de los españoles (y los de fuera en el interior de su territorio). Al desintegrarse ese nosotros se conforma un nuevo «nosotros» y un nuevo «ellos» o «los otros».

A pesar de estos atisbos de ruptura del unanimismo, los discursos en Euskadi se ven, todavía, alimentados por el juego de los contrarios; no permitir

12 En un análisis de la prensa nacionalista realizado por Ibarra Güel (1993), este autor encuentra que a partir de 1986 (momento de realización del trabajo de campo) comienza a percibirse un importante cambio en el discurso, que se acentúa a partir de 1988 (con el pacto de Ajuria Enea). A partir de este momento y hasta la actualidad, señala, podemos encontrar un viraje en la problemática central tratada por este tipo de discurso hacia temas como la paz y la normalización, restando centralidad a los clásicos argumentos de opresión y enfrentamiento (1993: 20). También Gurrutxaga (1990: 16) plantea la hipótesis de que el nacionalismo vasco vive un momento de «reinvención», de refundación de su sistema de referencia. Estos procesos de cambio de los discursos nacionalistas se pueden comenzar a atisbar en los discursos de los grupos de discusión que se analizan en esta investigación. 
que «los otros» ganen es una constante en la vida política vasca. La política nacionalista, así, se fundamenta en su oposición frente a la centralista, y viceversa. En este tipo de definición, por oposición, más que por diferencia, la posibilidad de identidades duales se hace difícil. En la dinámica de funcionamiento de esta política de discordia se incrementa la separación de lo que se ha llamado «la doble sociedad vasca». El enfrentamiento (la búsqueda de un enemigo) posibilita en mayor medida la unidad del grupo ("todos contra») frente a la amenaza común. Predomina una terminología e imágenes de conflicto ${ }^{13}$, con términos constantes relacionados con la semántica de la guerra («traición», "defensa», «resistencia», "lucha», «enemigo», "cobardía»), llegando a percibirse, en algunos casos, la situación extrema de guerra de todos contra todos. La participación se organiza, en mayor medida, en contra de algo, más que a favor. Afloran, no obstante, posturas en las que se aboga por la necesidad de tránsito hacia posiciones que no impliquen dualismos o enfrentamientos. De nuevo vuelve a emerger la conciencia del desarrollo de un proceso de transición desde la unidad y fraternidad nacionalista, hacia la apertura a lo complejo, lo múltiple, la diversidad interna, el conflicto en el seno de la sociedad y en el mismo nacionalismo. Este cambio implica una cierta ruptura del unanimismo que presidía la vida nacionalista vasca. Dicho proceso de transición comienza a producirse, en un primer momento, con el asentamiento de la democracia, acompañada de la formación y organización de diferentes partidos políticos (nacionalistas y estatales), con lo cual emergen unas diferencias internas explícitas y una competencia interior, especialmente con el acceso al poder de un (El) partido nacionalista (con la consiguiente emergencia de oposición ante la política llevada a cabo por el Gobierno vasco). Un segundo paso es el que se produce con la ruptura del $\mathrm{PNV}^{14}$, de la familia nacionalista, «de los de siempre». Emergen diferencias internas e intereses personalistas que resquebrajan la fantasía de la fraternidad nacionalista. La división nacionalista es difícilmente comprensible o legitimada y produce temor (especialmente por la dolorosa presencia de un nacionalismo tan fragmentado), que implica fractura de la propia comunidad. La aparición de la individualidad (ideologías partidistas, personalismos) frente a la familia (y su unidad) es vivido también dramáticamente. Este viraje constituye un ejemplo del proceso de asunción de la individualidad y el particularismo de la modernidad (politización, institucionali-

${ }^{13}$ Hay que recordar aquí la importancia que determinados autores, como el clásico Simmel, conceden al conflicto como elemento de socialización y de intensificación de la cohesión en el seno de los grupos afectados.

${ }_{14}$ En el momento de realización de los grupos de discusión el fenómeno de la escisión del PNV era muy reciente. Ello nos brinda la posibilidad de contar con un material verbal elaborado en un importante momento de afloramiento de las divisiones internas. Se debe considerar que «hasta los primeros años de la década de los ochenta resultaba inimaginable una hipotética división en un partido como el PNV, de boyante trayectoria y ventajosos resultados electorales, que representaba en Euskadi las mejores esencias de la reforma española y las hacía compatibles con una difícil reivindicación nacional» (García de Cortázar y Azcona, 1991: 144). 
zación e impersonalismo de las relaciones), con el abandono del «comunalismo" y el parentesco premodernos.

Por otra parte, en el segundo de los contextos que estamos analizando - Cataluña - la identificación con la "comunidad catalana» presenta un doble atractivo tanto en la población allí nacida como en la procedente de otras Comunidades Autónomas. La incorporación al proyecto catalán coincide con un proyecto de promoción social en el campo económico-social, y en el ámbito ideológico-afectivo supone la integración comunitaria. Esta doble articulación se apoya en un sustrato material de poder económico y político.

Catalán será todo aquel que vive y trabaja en Cataluña, abundando en la dimensión cívico-territorial y el carácter inclusivo e integrador del nacionalismo catalán. No obstante, a pesar de la continua referencia a criterios de índole subjetivista, en el proceso de adscripción a «lo catalán» emergen gradaciones de "catalanidad" relacionadas con la lengua (en función de las diferentes relaciones que se pueden mantener con ella: hablarlo, entenderlo, pensar en catalán, etc.), así como con el grado de nacionalismo activo.

Predomina la existencia de identificaciones duales (superposición de identidades), donde la pertenencia a Cataluña no es excluyente sino compatible con la pertenencia a España y a Europa ${ }^{15}$. Que el énfasis recaiga en uno u otro tipo de identificación depende de las circunstancias y los contextos en los que se elabora el discurso, siendo ésta una dualidad consciente y explícitamente razonada y coherente con la imagen pragmática que se entresaca de la caracterología catalana recurrentemente señalada por los participantes en los grupos.

Por otra parte, encontramos que la percepción de unanimismo, control y monopolio del nacionalismo es también importante, especialmente en relación a Convèrgencia i Unió. Sin embargo, la menor importancia de la concepción unitaria-familiar del nacionalismo catalán (casi desde sus orígenes) hace que este predominio adquiera partidarios y oponentes pero sin implicar ningún tipo de trauma, como sí lo hace, como acabamos de ver, en el caso vasco.

Aparece como rasgo explícito el reconocimiento de las diferencias internas aunadas en un proyecto común con carácter integrador de diversas comunidades de origen distinto, en competencia con aquello que se presenta como principal diferencia (con el Gobierno central) en la lucha por recursos económicos y poder del Estado. Así, las diferencias internas se negocian, se pactan, y los conflictos se dirimen en términos políticos en la confrontación entre partidos políticos competidores en juegos electorales. El enfrentamiento con Madrid (con el Gobierno central) se presenta en forma de negociación de parcelas y recursos. Las cosas se negocian, de forma sosegada y pactada, evitando el enfrentamiento abierto. Esto se hace posible por la asunción del «racionalismo» como marca de madurez y mandato social, adoptándolo como rasgo dis-

15 Reafirmando una vieja tradición catalana de soberanías compartidas y dependencias múltiples (Keating, 1996). 
tintivo de su propia comunidad. En esta línea, otro elemento destacable es la asunción de la mezcla, del sincretismo, en la configuración de la "personalidad catalana», lo cual desemboca en una visión integradora de Cataluña ${ }^{16}$.

\section{Dimensiones politicas}

En el caso vasco destaca la importancia de la política no institucionalizada canalizada, especialmente, a través de asociaciones, clubes y cuadrillas, como espacios y vehículos de socialización política que consiguen que lo político se haga cotidiano. La política invade todos los campos de la actividad humana en el seno de esta comunidad. Este rasgo, que ha caracterizado especialmente la etapa franquista, permanece todavía, en cierta medida, en el momento de la realización del trabajo de campo, si bien ha perdido buena parte de su efervescencia. Tras el establecimiento de la democracia y la institucionalización de los partidos políticos se fue desviando el mundo político desde las cuadrillas y la Iglesia a los partidos políticos (Pérez-Agote, 1987); "se reconduce la "calle" hacia soluciones institucionales» (Gurrutxaga, 1990: 16). La cuadrilla, que constituía un pilar básico en la movilización política y cultural durante el franquismo, pierde protagonismo como consecuencia de la aparición de estos nuevos espacios políticos. Así, el proceso de racionalización política y el control de las instituciones por parte del nacionalismo vasco vienen a modificar el planteamiento de la actividad de este movimiento ${ }^{17}$. Desde el momento en que se produce este desplazamiento comienza un proceso de separación, de divorcio entre la sociedad y la política, pasando esta última a ser percibida como actividad autónoma, profesionalizada e individualizada. Esta percepción implica una ruptura con el «comunalismo mítico» que forma parte de la tradición y, en consecuencia, de la construcción de la identidad vasca. La política, así, se transforma en algo segregador a lo cual se enfrentan con desconfianza.

Se observa también una divergencia entre las esferas económicas y políticas, una contradicción entre las exigencias nacionales y los propios intereses económicos, mostrándose el nacionalismo como obstáculo al desarrollo económico. Los conflictos sociales y económicos son percibidos como más graves que en otras comunidades como consecuencia de las especiales características de la confrontación política y la intervención del terrorismo y la violencia como freno al desarrollo económico y a la inversión. Junto a esto, el paro es vivido como el principal elemento que contribuye a la desintegración del País Vasco e incluso a la pérdida de horizonte de su propia cultura. La considera-

${ }^{16}$ Conversi (1993) señala la importancia de la definición que muchos intelectuales catalanes hicieron de su nación, como terra de pas (tierra de paso), como passadis (pasadizo) o melting pot, donde los elementos extranjeros pueden ser integrados sin destruir la cultura catalana.

${ }^{17}$ Este proceso parece invertirse en el momento actual, volviendo a imponerse en ciertos sectores la estrategia de "tomar la calle», así como la activación, usando la consigna «acción-represión-acción» y las contramanifestaciones. 
ción de la situación adopta una forma circular, en la que todos los elementos se entrecruzan, confirmando un círculo cerrado sin aperturas del cual apenas se ven salidas.

Así, se puede localizar una situación de "doble vínculo» ${ }^{18}$ según la cual lo que el pueblo vasco desearía por «sentimiento", lo dictado por "el carazón», entra en contradicción con los dictados de la razón. Lo económico se percibe como un factor que infunde miedo frente al sentimiento de pertenencia y la crisis económica se considera en relación con sus efectos disciplinarios sobre la acción política, al percibirse una contradicción entre la orientación de esta última y los requisitos necesarios para remontar la crisis.

Finalmente, encontramos diferentes formas y grados de autoridad y legitimidad politica ${ }^{19}$. La fundamental es la autoridad tradicional, que vendría de la mano del discurso manejado por el PNV y la legitimidad que le confiere la historia y la tradición del partido y del movimiento. También comienzan a percibirse signos de un tipo de autoridad racional-legal, especialmente a partir de la firma del Estatuto de Autonomía. A pesar de esto, este tipo de legitimidad se encuentra en situación de debilidad e inestabilidad, ya que el argumento de la no aceptación de la Constitución por parte del pueblo vasco permanece siempre presente, de forma que ésta no puede presentarse como símbolo de integración democrática. Así, la legitimidad legal-formal queda continuamente supeditada al proceso previo que implica la definición de la identidad vasca, modulado por el discurso desplegado por el tipo de autoridad tradicional, que basa gran parte de su fuerza en una política de «gestos» de oposición a dicha forma de legitimidad legal-formal.

Por otra parte, en Cataluña se asume totalmente la inclusión de la conflictividad nacionalista en el campo de la arena política, a través de la política institucionalizada de los partidos políticos. Se percibe la competencia entre los partidos políticos como algo positivo que acaba redundando en el beneficio de los propios intereses de los ciudadanos, adoptándose, incluso, estrategias de voto para que tal competencia se incremente (por ejemplo, voto a un partido en las elecciones autonómicas y a otro diferente en las generales o municipales). De esta forma, el voto se convierte en el resultado de una especie de cálculo racional, produciéndose un importante trasvase de votos según el tipo de convocatoria. Se entresaca la relevancia de evitar el monopolio por parte de un solo partido (se habla, incluso, de diferentes "casas" a cuidar).

En cuanto a la vinculación entre lo político y lo económico, se observa un reconocimiento explícito de la necesidad de abordar conjuntamente todas las esferas (incluidas también las culturales). Aparece un especial hincapié en el pragmatismo, el control de los afectos, poniéndose especial énfasis en la lucha

18 Sobre el concepto de "doble vínculo», ver el trabajo de Watzlawick, Babelas y Jackson (1991: 173 y ss.).

19 Siguiendo el argumento de Conde (1989), que aplica los tipos puros de dominación y legitimidad de Weber al caso vasco. 
por los recursos del Estado. No se percibe contradicción, sino coincidencia, entre las exigencias nacionales y los propios intereses económicos. El tipo de política concreta que se está realizando desde el Gobierno catalán se muestra coincidente con los intereses del ciudadano, al tiempo que la competencia entre las diferentes instancias de poder (Gobierno central, Generalitat, Ayuntamientos) redunda en beneficio del propio país. Paralelamente, el mantenimiento de un importante grado de ambigüedad y confusión en torno a las competencias transferidas a esta Comunidad Autónoma aumenta la eficacia de argumentos de exculpación y legitimación institucional.

Finalmente, en lo relacionado con la legitimidad politica (vista en el caso anterior) predomina un tipo de autoridad racional-legal que descansaría básicamente en la aceptación de la Constitución y la firma del Estatuto de Autonomía. Se caracteriza por una asunción de la conflictividad nacionalista en términos de política institucionalizada, regulada legalmente, y así consensuada. A su vez, este tipo de legitimidad convive con un tipo de autoridad carismática, que en el caso de Cataluña vendría a estar representada y condensada en la figura de Pujol, al cual se identifica no sólo con la totalidad del partido al que representa, sino con el nacionalismo, la Generalitat y, por ende, Cataluña.

\section{Gráficos-resumen de las "hablas hegemónicas» localizadas}

Para terminar este apartado se ofrecen unas tablas-resumen del contenido entresacado de cada uno de estos dos discursos. Estas tablas pueden ser leídas tanto en sentido horizontal, para captar el aspecto comparativo de ambos discursos, como en sentido vertical, reelaborando, así, el tipo de discurso nacional que se ha ido describiendo. 


\section{TABLA 1}

\section{"Hablas hegemónicas» en País Vasco y Cataluña}

\begin{tabular}{|c|c|c|}
\hline \multirow[b]{3}{*}{$\begin{array}{l}\text { El territorio } \\
\text { y la Historia }\end{array}$} & PAÍS VASCO & CATALUÑA \\
\hline & \multicolumn{2}{|c|}{ Elementos diferenciales entresacados } \\
\hline & $\begin{array}{l}\text { - Genealogía. } \\
\text { - Comunidad «social». } \\
\text { - Nación como "familia». } \\
\text { - Nostalgia del pasado, ausencia } \\
\text { de proyecto de futuro. } \\
\text { - Pesimismo, sensación de preca- } \\
\text { riedad, desmarque. } \\
\text { - Nación vasca por encima de los } \\
\text { avatares históricos. } \\
\text { - Inmutabilidad de las esencias } \\
\text { vascas. } \\
\text { - Franquismo: nuevo mito funda- } \\
\text { cional (período de unidad nacio- } \\
\text { nalista frente a la opresión). }\end{array}$ & $\begin{array}{l}\text { - Territorio. } \\
\text { - Comunidad político-legal. } \\
\text { - Nación como «casa». } \\
\text { - Orientación hacia el futuro (más } \\
\text { tendencias que metas). } \\
\text { - Optimismo. } \\
\text { - Dimensión histórica y de clase } \\
\text { más concreta. }\end{array}$ \\
\hline
\end{tabular}

Limites y simbolos - Esencias inmutables, autorreferentes.

- Símbolos de la nación: ikurriña, himno, euskera, ertzaintza (dotados de legitimidad histórica).

- Comparación con el pueblo judío: persecución, diáspora, pérdidas.

- Comunitarismo.

- No sometimiento.

- Lucha por la libertad.

- Valoración del pasado rural.

- Sentimentalismo (valoración más positiva que la racionalidad).
- No esencialismo.

- Símbolos de la nación: lengua catalana, la senyera, himno, Generalitat, progresía cultural y política.

- Herencia fenicia.

- Pragmatismo.

- Pactismo.

- Moderantismo.

- Valoración de la competencia.

- Racionalidad.

- Cooperativismo por consensualismo.

- Negociación.

- Adaptabilidad «manejando».
- «Hecho único», exclusividad y originalidad.

- Principal medio diferenciador.

- Medio de conquistar el «estatus nacional» y vía de "estatus social».

- Vivido traumáticamente por su estado de recesión (se suma la dificultad de su aprendizaje).

- Usado como arma política arrojadiza.

- Desligamiento del nacionalismo.
- «Hecho diferencial». Principal rasgo síntesis de la diferencialidad catalana.

- Medio de integración social y laboral.

- Posición hegemónica del catalán.

- No problemático.

- Aceptación del biligüismo (aunque conflictividad linguística a nivel cotidiano). 


\section{TABLA 1 (continuación)}

\section{"Hablas hegemónicas» en País Vasco y Cataluña}

\begin{tabular}{|c|c|c|}
\hline \multirow[b]{3}{*}{$\begin{array}{l}\text { Pertenencia } \\
\text { e identidad }\end{array}$} & PAÍS VASCO & CATALUÑA \\
\hline & \multicolumn{2}{|c|}{ Alteridad, identidad y conflicto } \\
\hline & $\begin{array}{l}\text { - Pertenecer al País Vasco=luchar } \\
\text { por él, defenderlo=ser naciona- } \\
\text { lista. } \\
\text { - Crisis de identidad que lleva a } \\
\text { aferrarse fuertemente a las señas } \\
\text { de identidad. } \\
\text { - Conciencia de descentramien- } \\
\text { to («haber dejado de ser al- } \\
\text { guien»). } \\
\text { - Identificación Euskadi=Naciona- } \\
\text { lismo. } \\
\text { - Principal división: nacionalista/ } \\
\text { no nacionalista (posibilidad de } \\
\text { integración por esa vía). } \\
\text { - En términos duales, de oposi- } \\
\text { ción: si no eres nacionalista eres } \\
\text { antinacionalista=antivasco. } \\
\text { - Identidad excluyente. } \\
\text { - Fuerte división nosotros/ellos. } \\
\text { - Actualidad: momento de descen- } \\
\text { tramiento y desestructuración } \\
\text { del campo del nosotros (unido a } \\
\text { crisis económica y crisis del } \\
\text { nacionalismo). Nuevos «noso- } \\
\text { tros» y nuevos «ellos» como con- } \\
\text { secuencia de la división del } \\
\text { nacionalismo, pactos... }\end{array}$ & $\begin{array}{l}\text { - Pertenecer a Cataluña=sentirse } \\
\text { catalán. } \\
\text { - Identificación de lo catalán como } \\
\text { «lo burgués»=promoción de clase } \\
\text { e integración comunitaria. } \\
\text { - Catalán el que vive y trabaja en } \\
\text { Cataluña (dimensión territorial). } \\
\text { - Grados de catalanidad relaciona- } \\
\text { dos con la lengua y el nacionalis- } \\
\text { mo activo. } \\
\text { - Importante delimitación: la } \\
\text { voluntad de ser catalán. } \\
\text { - Superposición de identidades no } \\
\text { excluyentes (Cataluña, España, } \\
\text { Europa). }\end{array}$ \\
\hline
\end{tabular}

Unidad y diferencia. - Nación: homogénea, por encima Diferencia y conflicto de las clases y las diferencias ideológicas.

- El "otro» también en términos de igualdad y homogeneidad.

- Momento de transición de la unidad y la fraternidad nacionalista hacia la apetura hacia lo complejo y lo múltiple=Ruptura del unanimismo (primero con la aparición de diferentes partidos políticos, segundo con la división del nacionalismo).

- División del PNV vivida como proceso doloroso, no comprensible, no aceptado.
- Unanimismo del nacionalismo sintetizado en $\mathrm{CiU}=$ implica adherentes y oponentes, pero no trauma.

- Reconocimiento de las diferencias internas subsumidas bajo un proyecto común con carácter integrador de las diversas comunidades (posibilidad de integración por diferentes vías) en una lucha común por recursos y poder del Estado.

- Las diferencias se negocian, se pactan.

- Inclusión en España, aunque "hecho diferencial» (identidad dual). 


\section{TABLA 1 (continuación)}

\section{"Hablas hegemónicas» en País Vasco y Cataluña}

\section{PAÍS VASCO CATALUÑA}

- De la «familia» nacionalista (el partido) a la emergencia de los personalismos y la individualidad (fuerte carga emocional).

- Añoranza de épocas de unidad.

- Discursos alimentados por el juego de los contrarios.

- No permitir que los "otros» ganen.

- Unidad frente al "otro" (Madrid, Gobierno central, partidos estatales, etc.).

- Política nacionalista frente a centralista, y viceversa: política de discordia (se ahonda en la "doble sociedad vasca»).

- Terminología e imágenes de guerra (traición, defensa, resistencia, lucha, enemigo, cobardía, etc.).

- Necesidad de tránsito hacia posiciones no duales.

- Carácter defensivo de la identificación.
- Asunción de la mezcla como carácter diferenciador=desemboca en una visión integradora.

- Hegemonía nacionalista identificada con $\mathrm{CiU}$ disuade frente a la crítica.

- Confrontación en términos políticos, entre partidos (juego electoral), en la atribución de méritos, realizaciones y responsabilidades.

- Enfrentamiento con Madrid en términos de negociación, evitando la confrontación abierta (posible por la asunción de la racionalidad como rasgo diferenciador de lo catalán y como mandato social).

- Definición en términos de diferencialidad más que de conflicto en la búsqueda de reconocimiento de su singularidad.

- Carácter asertivo de la identificación.

\section{Dimensión política}

Partidos políticos

- Lo político, instalado en lo cotidiano (importancia de las cuadrillas).

- Con aparición de partidos políticos=desviación del mundo político.

- Divorcio sociedad civil/política (como actividad autónoma y profesionalizada). Lo político= un nuevo "otro": contribuye a la ruptura del «comunalismo mítico".

- La política se transforma en algo culpable, segregador, divisor.
- Inclusión de la conflictividad nacionalista en el juego partidista.

- Competencia entre partidos buena; redunda en beneficios sociales.

- Estrategias de voto para conseguir dicha competencia (trasvase de votos según el tipo de convocatoria, "diferentes casas a cuidar»). 


\section{TABLA 1 (continuación)}

\section{"Hablas hegemónicas» en País Vasco y Cataluña}

\begin{tabular}{|c|c|c|}
\hline & PAÍS VASCO & CATALUÑNA \\
\hline $\begin{array}{l}\text { La economía } \\
\text { y la politica }\end{array}$ & $\begin{array}{l}\text { - «Doble vínculo» de lo nacional y } \\
\text { lo económico (en términos de } \\
\text { valentía o egoísmo). } \\
\text { - Exigencias nacionales, en contra- } \\
\text { dicción con los propios intereses. } \\
\text { - Percepción del divorcio entre } \\
\text { política y economía. } \\
\text { - Políticas partidistas. } \\
\text { - Crisis económica supeditada a } \\
\text { normalización política (=freno } \\
\text { económico). } \\
\text { - Círculo cerrado sin posibilidad } \\
\text { de apertura. } \\
\text { - EEl miedo de lo económico». } \\
\text { económica. }\end{array}$ & $\begin{array}{l}\text { - Problemáticas a acometer conjun- } \\
\text { tamente. Hincapié en el pragma- } \\
\text { tismo. } \\
\text { - Exigencias nacionales confluyen y } \\
\text { se superponen con los propios } \\
\text { intereses. } \\
\text { - Lo político percibido como favo- } \\
\text { recedor de lo económico (dimen- } \\
\text { sión de clase del nacionalismo } \\
\text { catalán). } \\
\text { - Enfrentamiento político=compe- } \\
\text { tencia=beneficioso para el ciuda- } \\
\text { dano= legitimación institucional. }\end{array}$ \\
\hline Legitimidad política & $\begin{array}{l}\text { - Autoridad tradicional (PNV). } \\
\text { - Autoridad racional-legal (por } \\
\text { acuerdo sobre el Estatuto); pre- } \\
\text { cariedad por emergencia del } \\
\text { argumento de no aceptación de } \\
\text { la norma básica (la Constitución) } \\
\text { Paralelo al descreimiento de las } \\
\text { instituciones políticas (elevados } \\
\text { índices de abstencionismo). }\end{array}$ & $\begin{array}{l}\text { - } 1 .^{\circ} \text { Autoridad racional-legal. } \\
\text { 2. A Autoridad carismática (líder } \\
\text { CiU). }\end{array}$ \\
\hline
\end{tabular}

\section{«HABLAS ESPECÍFICAS» LOCALIZADAS EN PAÍS VASCO Y CATALUNA}

Como se ha señalado en apartados anteriores, de la misma manera que el discurso nacionalista "hegemónico» varía en los elementos priorizados, en terminología y contenido en función del contexto territorial, también encontramos que el discurso nacional encuentra interpretaciones y "de-codificaciones» diferenciales en relación con los distintos contextos socioeconómicos y en función de los diferentes grupos sociales en el seno de ambas sociedades.

Se han denominado "hablas especificas» a esas diferentes elaboraciones discursivas que se construyen sobre la nación en un contexto determinado en función de los diversos fraccionamientos sociales. Hay que tener presente que estas "hablas específicas» se desarrollan en contextos político-gubernamentales 
y comunicacionales concretos, en los cuales se manifiestan "hegemónicamente» las hablas que en el capítulo anterior fueron reseñadas.

Se van a describir, a grandes rasgos y muy esquemáticamente, los principales discursos que encontramos y las características generales de los grupos que los sustentan. Hacemos una mención a los discursos encontrados en el contexto vasco, para pasar, en segundo lugar, a abordar escuetamente el catalán. Cada uno de los discursos localizados requeriría un análisis exhaustivo para una mejor comprensión de los elementos que los componen, de sus estrategias, de su formación y reproducción. Se ofrece un panorama global que muestra la presencia de diferentes discursos ubicados en posiciones diversas en el continuum étnico-cívico que se ha descrito, así como la existencia de discursos en dos dimensiones o niveles de la identidad nacional, esto es, la vasca y la catalana, por una parte, y la española, por otra. La pertenencia de los sujetos a grupos con características socioestructurales diversas, así como el carácter de la pertenencia étnico-nacional, condicionan la mayor o menor proximidad a cada uno de ellos.

\section{País Vasco}

En el caso del País Vasco encontramos, en primer lugar, que en el momento de realización del trabajo de campo la emergencia de divisiones internas (sociales y políticas) conlleva una percepción de fragmentación y falta de cohesión social más exacerbada que en el resto del Estado español. Estas fragmentaciones en el seno del País Vasco son vividas angustiosamente. Implican, muchas veces, conflictos en diversos órdenes; más concretamente, en el ámbito de la concepción nacional, llevan aparejados posicionamientos, actitudes, percepciones y maneras de actuar divergentes relacionados con la nación y el nacionalismo.

Se han entresacado cuatro diferentes tipos de discursos que se podrían ubicar en el continuum étnico-cívico de construcciones de la identidad nacional relacionados con los rasgos defensivo-asertivos comentados anteriormente.

Uno es el discurso defensivo étnico, que viene a ser el que se aproxima en mayor medida al discurso anteriormente expuesto para el caso vasco, aunque con un predominio más acentuado de los rasgos de especificidad étnica como definición identitaria relacionada con un grupo emparentado. Destacan en este tipo de discurso las concepciones dualistas de la sociedad y el unanimismo en la percepción del propio grupo nacional. Predomina en la población de mayor edad, de Vizcaya y, fundamentalmente, en sectores de comerciantes, pequeños empresarios y funcionarios medios, cuya simpatía en términos de partidos políticos se aproxima, en mayor medida, al discurso ofertado por el PNV.

Se ha desvelado, también, un discurso "defensivo-antisistema», caracterizado por el vocabulario de la confrontación y la oposición. En él predomina una visión polarizada de la sociedad y de la movilización política (expresada fundamentalmente en terminología antirrepresiva) y un fuerte radicalismo. Prevalece 
entre la población más joven de esta comunidad, en sectores económicos segregados de la estructura laboral y, en mayor medida, en Guipúzcoa. El partido que en mayor medida se aproxima a este tipo de demandas es la coalición HB.

En tercer lugar, se ha desvelado la existencia de un tercer discurso al que hemos denominado "asertivo civico-territorial». Es éste un discurso que está caracterizado fundamentalmente por el hincapié en la diferencia vasca, pero con asunción de las fracturas y la diversidad interna. No implica una relación defensiva con «lo español», sino una posición afirmativa, expresada en términos de especificidad o diferencia pero no enfrentamiento. Se localiza fundamentalmente en posiciones más estables y, en mayor medida, dependientes del exterior de la comunidad autónoma vasca como, por ejemplo, entre los profesionales liberales, empresarios y ciertos sectores de funcionarios. Predomina en la provincia de Guipúzcoa, sin una clara delimitación de los grupos de edad en los cuales es preponderante. Dos son los partidos políticos cuyos planteamientos pueden "captar» este tipo de discurso, uno de carácter más netamente nacionalista (Eusko Alkartasuna) y otro con mayor proximidad a posiciones "centralistas», esto es, Euskadiko Eskerra ${ }^{20}$.

Para terminar, se ha localizado, enfatizando otro de los niveles de identidad y pertenencia, el discurso que hemos llamado "discurso defensivo españolista», que presenta rasgos que ponen de relieve un cierto grado de enfrentamiento y defensa frente al conjunto de los discursos nacionalistas vascos. Destaca la presencia de este último tipo de discurso en el grupo de población inmigrante, especialmente en el sector de los trabajadores. Las provincias en las que se localiza principalmente (en términos comparativos) son las de Vizcaya y Álava y, en relación con la edad, es el grupo poblacional de mayor edad aquel en el que destacan este tipo de elaboraciones y posicionamientos.

\section{Cataluña}

En términos generales, encontramos en el caso catalán que la percepción de fragmentación extrema que caracterizaba el caso vasco no está presente. Más al contrario, prevalece una vivencia de un mayor consenso relacionado con las cuestiones «nacionales», en el cual las principales divergencias vienen caracterizadas por el propio carácter de la contienda política, así como por la orientación ideológica, en términos tradicionales de izquierda y derecha, vinculado, también, al conflicto de carácter cultural, que se centra, básicamente, en la lengua. En el continuum étnico-cívico que definimos en anteriores apartados, el conjunto de los discursos que se han localizado se encuentra, en bloque, desplazado hacia el polo ideal-típico que denominamos cívico-territorial.

Se han entresacado cuatro diferentes discursos, a los cuales corresponden,

${ }^{20}$ Pocos años más tarde, concretamente en 1993, este partido pasó a coaligarse con el PSE. 
en términos generales, determinadas posiciones socioestructurales. Estos discursos van a ser descritos sucintamente, como en el caso anterior.

Se localiza un primer discurso que hemos denominado «discurso victimista catalanista», más próximo al polo étnico, en términos comparativos, si bien presenta una gran diferencia con el que vimos reflejado en el caso vasco. Viene a estar caracterizado por el planteamiento continuo de agravios por el perjucio de la pertenencia al Estado español. Prevalece una visión, en mayor medida, comunitarista e interclasista del vínculo nacional. Se puede ubicar en ciertos grupos de agricultores y pequeñas burguesías locales, en sectores de población de mayor edad, en provincias y localidades que no corresponden con Barcelona capital y con una mayor proximidad al discurso de CiU.

Podemos encontrar un segundo discurso etiquetado "discurso autonomista de enfrentamiento». Se aproxima en buena medida a lo que vimos en la descripción de las hablas hegemónicas en el contexto catalán. Destaca la definición de la problemática nacional en términos de estrategia en una búsqueda de confrontación con el poder central por los recursos del Estado, así como fuente de legitimidad interna. Se presenta prioritariamente en ciertos sectores del empresariado, comerciantes, funcionarios y fracciones acomodadas de las clases trabajadoras. Donde se puede localizar en mayor medida este discurso es fuera de Barcelona capital y su corona metropolitana. El partido que mejor se acomoda a sus prioridades vuelve a ser $\mathrm{CiU}$.

El tercero de los discursos que se ha localizado ha sido denominado «discurso asertivo cívico-territorial catalanista». Es un discurso no autocentrado exclusivamente en Cataluña. Se presenta abierto a varios niveles de identidad nacional y tiene en consideración las importantes diferencias y conflictos en el seno de esta comunidad. Predomina en sectores de profesionales, estudiantes y trabajadores autóctonos, en grupos de edad media, así como en los más jóvenes, $y$, fundamentalmente, en Barcelona. Los partidos que se pueden considerar que son los principales soportes de este tipo de discurso son aquellos que corresponden al espectro de la izquierda catalana, IC y PSC.

Finalmente, se ha desvelado un tipo de discurso correspondiente al nivel de identidad más netamente español que no adquiere un carácter tan defensivo como lo que se observó en el caso vasco. Le hemos denominado «discurso autonomista cívico-territorial español» y se ha localizado, fundamentalmente, en el grupo de los trabajadores inmigrantes de mayor edad, concentrados en mayor medida en Barcelona, y que constituyen el principal soporte del voto al PSOE.

\section{CONCLUSIONES}

Se han delimitado dos clases de discursos («tipos ideales» en términos weberianos) «hegemónicos» diferenciados, en el caso del nacionalismo catalán y el vasco. Estos dos discursos que enfatizan y ponen de relieve diferentes aspectos de la nación se aproximan (siempre en relación el uno con el otro) a 
dos formas "prototípicas» de construir la nación; uno es el discurso étnico y otro el cívico-territorial.

El caso vasco se encuentra más próximo (siempre en relación al catalán) al tipo étnico y en él asienta básicamente su simbología e imaginería. Este discurso, quebrado por diferentes acontecimientos de la historia de esta nación (como son el avance industrializador, la ruptura de la unidad antifranquista, la institucionalización y llegada al poder de los partidos nacionalistas, la escisión del Partido Nacionalista Vasco, la emergencia de la individualidad y el personalismo o la crisis económica), se ve desplazado hacia elaboraciones que van aproximándose al que hemos denominado cívico-territorial. Por otra parte, el nacionalismo "hegemónico» en el caso catalán se sitúa más próximo al tipo de discurso cívico-territorial, con las características que a él fueron atribuidas.

El predominio de elementos de uno u otro discurso no es estable, sino que varía en función de los grupos sociales (relacionados con los grupos de edad, de clase social, de procedencia geográfica, etc.) que reconstruyen dicho discurso. Así pues, conviviendo con los discursos «hegemónicos» y en el seno de ellos encontramos diversos posicionamientos en el eje de articulación de la tensión entre ambos polos de construcción del discurso nacional (polo cívico-territorial y polo étnico). Las elaboraciones discursivas que se encuentran en los diferentes grupos sociales responden, en buena medida, a posiciones diversas en el seno de la estructura social en la que se engendran. Se relacionan, fundamentalmente, con posiciones de mayor o menor estabilidad, que conllevan manifestaciones de tipo defensivo (en el caso del predominio de posiciones o contextos de inestabilidad) o afirmativo (en el caso contrario), que a su vez conducen a aproximaciones a uno u otro extremo de los que se han propuesto. La relación básica consiste en una mayor aproximación al tipo étnico donde prevalecen posicionamientos defensivos y una mayor cercanía al cívico en el supuesto de posiciones asertivas. En función de estas características hemos encontrado elaboraciones de diferentes discursos que cubren la gama de posibilidades entre uno y otro polo, según si éstas representan reelaboraciones victimistas, defensivas-reactivas, asertivas, etc.

En el gráfico 1 aparecen topológicamente representados algunos de los principales elementos que han sido desarrollados en las páginas precedentes. 


\section{GRÁFICO 1}

\section{Representación topológica del análisis de discursos comparando el País Vasco y Cataluña}

\section{O S C I L A C I Ó N}

\begin{tabular}{|l|}
\hline Discurso \\
nacionalista \\
étnico
\end{tabular}

- Hincapié en los ancestros.

- Importancia de los antepasados comunes, de la familia.

- Comunidad cultural.

- Importancia de la lengua y de las costumbres.

- Proyección de pasado.

- Importancia de la reconstrucción de la Historia.

- Legitimidad tradicional o carismática.

- Dualismos en la percepción de lo social («nosotros/ellos»).

- Exclusivismo identitario.

- Comunalismo.

- Importancia de las relaciones de afectividad.

- Unanimismo del «nosotros".

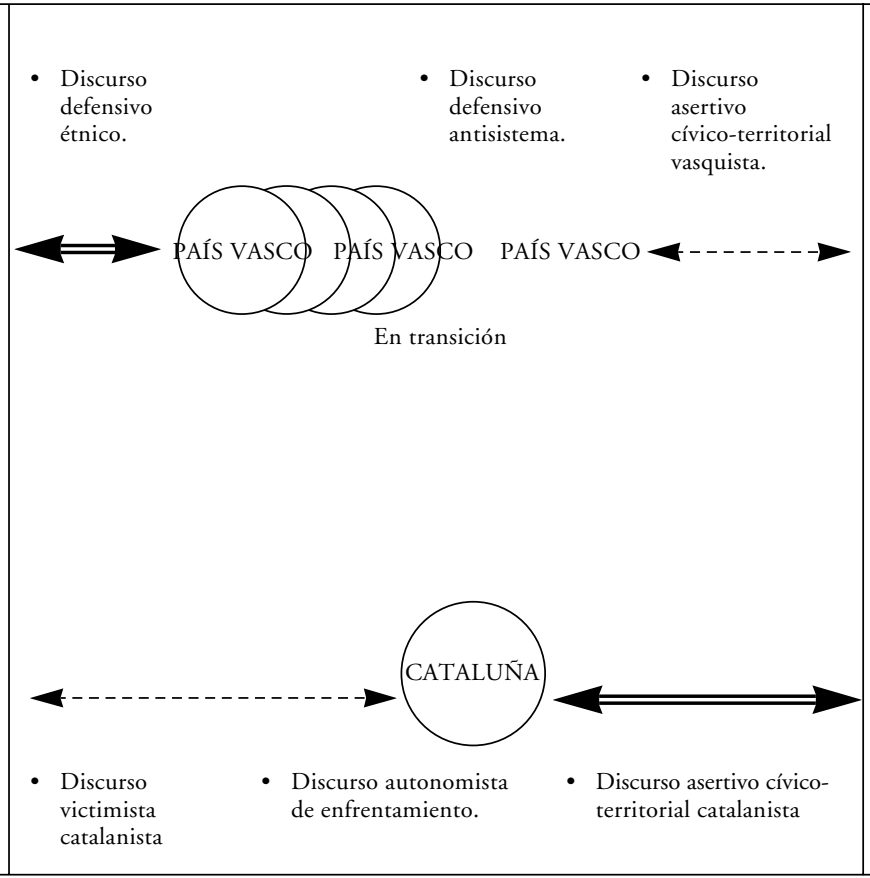

\begin{tabular}{|l|}
\hline Discurso \\
nacionalista \\
cívico
\end{tabular}

- Convivencia común.

- Acuerdo social.

- "Casa” común.

- Comunidad política.

- Proyección de futuro.

- Legitimidad legal-formal.

- Multiplicidad social.

- División interna.

- Compatibilidad de identidades.

- Individualismo. Personalismo.

- Importancia de las relaciones pragmáticas.

- Negociación política

- Estrategia.

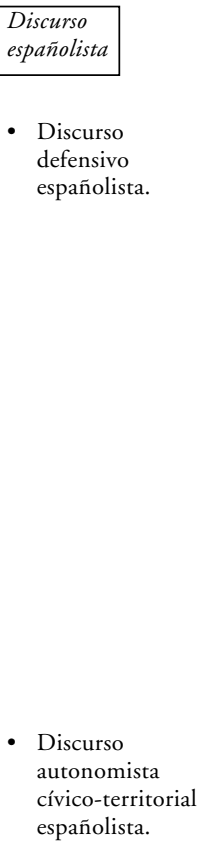




\section{ANEXO METODOLÓGICO}

\section{Grupos de discusión en el País Vasco}

Hemos contado con doce grupos de discusión pertenecientes a dos diferentes estudios:

a) Estudio cualitativo País Vasco. CIS. Noviembre 1986: 9 grupos.

- RG núm. 1: Grupo constituido por obreros y empleados, 35-45 años. Portugalete (Vizcaya).

- RG núm. 2: Grupo de empresarios y comerciantes. Mixto de 35-45 años. Elorrio (Vizcaya).

- RG núm. 3: Grupo de jóvenes de ambos sexos, de 19 a 23 años. Bilbao.

- RG núm. 4: Grupo de jóvenes de ambos sexos, de 20 a 24 años. San Sebastián.

- RG núm. 5: Grupo de profesionales y empresarios, de 38-48 años. Mixto (Guipúzcoa).

- RG núm. 6: Grupo de funcionarios, profesionales y empresarios. Mixto de 35 a 45 años. Vitoria.

- RG núm. 7: Grupo de profesionales liberales, de 32 a 40 años. Próximos al PSOE. Bilbao.

- RG núm. 8: Grupo de pequeños empresarios y comerciantes. 45-55 años. Bilbao.

- RG núm. 9: Grupo de funcionarios y administrativos medios, de 40 a 50 años. Próximos al PNV. San Sebastián.

b) Estudio sobre secularización. Grupos del País Vasco. 1987: 3 grupos.

- RG núm. 10: Grupo de amas de casa en torno a los 40 años. Guetaria. San Sebastián (una inmigrante).

- RG núm. 11: Grupo de empresarios. En torno a los 40 años. Mondragón.

- RG núm. 12: Grupo de trabajadores de edad media. Inmigrantes. Baracaldo.

El diseño por el cual fueron seleccionados estos grupos responde a criterios de distribución de la población en función de dos dimensiones fundamentalmente —estatus e ideología—, teniendo en cuenta, además, las variables adicionales edad, provincia y procedencia geográfica. 


\section{Grupos de discusión en Cataluña}

La fecha de realización del trabajo de campo fue noviembre 1987 y el número total de grupos que se llevaron a cabo fueron nueve. El diseño de los grupos, siguiendo los mismos criterios que en el caso anterior, fue el siguiente:

- RG núm. 1: Grupo de obreros inmigrantes de la primera generación de 40 a 50 años y trabajadores industriales del cinturón de Barcelona.

- RG núm. 2: Grupo de jóvenes, hijos de inmigrantes. Mixto. De 19 a 23 años. Hijos de trabajadores industriales del cinturón de Barcelona.

- RG núm. 3: Grupo de amas de casa (4) y trabajadoras (4) de 28-35 años. Cuatro catalano-parlantes y cuatro castellano-parlantes. Clase media y media-baja. Barcelona.

- RG núm. 4: Grupo de hombres, empresarios, profesionales y ejecutivos de empresa, 40 a 50 años. Tarragona. Un subnúcleo inmigrante.

- RG núm. 5: Grupo de hombres agricultores de 45 a 55 años. Vich (Barcelona).

- RG núm. 6: Grupo de profesionales de ambos sexos de 32 a 40 años. Barcelona.

- RG núm. 7: Grupo de universitarios de ambos sexos, 21 a 24 años. Barcelona.

- RG núm. 8: Grupo de Amas de casa de 35 a 45 años. Clases medias. Lérida.

- RG núm. 9: Grupo de profesionales liberales de ambos sexos. Afiliados y próximos al PSC-PSOE. Barcelona.

\section{REFERENCIAS BIBLIOGRÁFICAS}

AlONSO, L. E. (1995): «Sujeto y discurso: El lugar de la entrevista abierta en las prácticas de la Sociología Cualitativa», en J. M. Delgado y J. Gutiérrez, Métodos y técnicas cualitativas de investigación en Ciencias Sociales, Madrid, Ed. Síntesis Psicológica, pp. 225-240.

Ayerbe, M.; BuenetXeA, E., et al. (1996): Los valores en la comunidad autónoma del País Vasco y Navarra. Su evolución en los años 1990-1995, Vitoria-Gasteiz, Servicio Central de Publicaciones del Gobierno Vasco.

BHABHA, H. K. (1990): Nation and Narration, London, Routledge.

Cabrera VARela, J. (1992): La nación como discurso: la estructura del sistema ideológico nacionalista: el caso gallego, Madrid, CIS, Monografía núm. 126.

COnde, F. (1989): "Los principios de legitimidad política en el caso vasco», en A. PÉreZAgote, Sociología del Nacionalismo, Servicio Editorial, Universidad del País Vasco.

CONVERSI, D. (1990): «Language or Race? The choice of core values in the development of Catalan and Basque nationalism", Ethnic and Racial Studies, vol. 13, núm. 1, enero, pp. 50-70.

- (1993): "Violence as an Ethnic Border. The Consecuences of a Lack of Distintive Elements in Croatian, Kurdish and Basque Nationalism», trabajo presentado al International Congress "Nationalism in Europe: Past and Present", Santiago de Compostela, 27-29 de septiembre, Pre-Actas. 
Estradé, M. A. (1989): Del catalanisme possibilista al nacionalisme radical, Ed. Virgili \& Pagès, S.A.

García de Cortázar, F., y Montero, M. (1980): Historia contemporánea del País Vasco, San Sebastián, Txercoa.

García Ferrando, M.; López-Aranguren, E., y Beltrán, M. (1994): La conciencia nacional y regional en la España de la autonomías, Madrid, CIS.

GELlNER, E. (1987): Naciones y nacionalismo, Madrid, Alianza Editorial (1.a ed., 1983).

- (1989): Identidad politica. Cambio y nacionalismo, Barcelona, Ed. Gedisa (1. a ed., 1987).

- (1993): «El nacionalismo y las dos formas de la cohesión en las sociedades complejas», en Delannoi y Taguieff (comps.), Teorías del Nacionalismo, Barcelona, Paídós, pp. 333-365 (extraído y traducido de Gellner, Culture, Identity \& Politics, Cambridge University Press, 1987).

GurrutXagA, A. (1990): La refundación del nacionalismo vasco, Bilbao, Servicio Editorial de la Universidad del País Vasco.

- (1992): "La búsqueda del extraño», en C. Moya, A. Pérez-Agote et al. (comps.), Escritos de Teoría Sociológica. En homenaje a Luis Rodríguez Zúñiga, Madrid, CIS, pp. 463-477.

GurrutXaga, A., y UnCETA, A. (1995): «Nacionalismo vasco y democracia: Crítica de la doctrina central», Sistema, núm. 124, enero.

IBARRA GÜEL, P. (1993): "La evolución a través de su discurso del nacionalismo vasco radical», trabajo presentado al International Congress "Nationalism in Europe: Past and Present", Santiago de Compostela, 27-29 de septiembre, Pre-Actas.

Kedourie, E. (1985): Nacionalismo, Madrid, Centro de Estudios Constitucionales.

Keating (1996): "Cataluña», en Naciones contra el Estado. Cataluña, Escocia y Quebec, Ariel Ciencia Política, pp. 143-196.

Llera Ramo, F. J. (1992): "Conflicto en Euskadi, diez años después», Inguaruak. Revista Vasca de Sociología, núm. 7, pp. 83-118.

LÓPEZ-ARANGUREN, E. (1995): «Las dimensiones de la conciencia nacional y regional», REIS, núms. 71-72, julio-diciembre, pp. 41-77.

Mata, J. M. (1993): El nacionalismo vasco radical: Discurso, organización y expresiones, Bilbao, Servicio Editorial del País Vasco.

PéReZ-Agote, A. (1986): La reproducción del nacionalismo: el caso vasco, Madrid, CIS y S. XXI (1. a ed., 1984).

- (1987): El nacionalismo vasco a la salida del Franquismo, Madrid, CIS.

SERrANO, A. (1995): "Nacionalismo y clases sociales en dos contextos de nacionalismo en España», en J. Carabaña (ed.), Desigualdad social y clases sociales: Un seminario en torno a Erik Olin Wright, Madrid, Ed. Visor y Argentaria.

- (1997): "Naciones y sistema educativo», en M. Fernández EnguiTA, Sociología de la Educación, Barcelona, Ed. Horsori.

Smith, A. D. (1976): Las Teorías del Nacionalismo, Barcelona, Península (1.a ed., 1971).

- (1986): The ethnic origins of Nations, Oxford, Basil Blackwell.

- (1991): National Identity, London, Penguin Books.

TeXIER, J. (1975): Gramsci, teórico de las superestructuras, México, Ed. Cultura Popular.

Watzlawick, P.; Bavelas, J. B., y JacksOn, D. D. (1991): Teoría de la comunicación humana, Barcelona, Herder. 


\begin{abstract}
This paper presents a comparative study of the manifestations of nationalist discourses in the Basque Country and Catalonia. It springs from the premise that the development of nationalist discourses (the "code» in linguistic terms) springs from a set of basic elements and that it becomes specific in specific contexts, adopting variable forms in which various elements are prioritised («nationalist-speak»). The different discourses range between two «ideal-typical» poles of manifestation of nationalism: the ethnic pole and the civic-territorial pole. The specific positions in the continuum formed by these two poles depend on characteristics such as the groups which form their main support, predominant ideological traditions or the cultural, political and economic context in which they develop.
\end{abstract}

